Research Article

\title{
Fuzzy Principal Component Analysis Model on Evaluating Innovation Service Capability
}

\author{
Hui Wu and Xiao-min Gu (iD \\ School of Financial Technology, Shanghai Lixin University of Accounting and Finance, 995 Shangchuan Road, Pudong New Area, \\ Shanghai 201209, China
}

Correspondence should be addressed to Xiao-min Gu; guxiaomin@lixin.edu.cn

Received 9 June 2020; Revised 23 June 2020; Accepted 26 July 2020; Published 30 September 2020

Academic Editor: Lu Zhen

Copyright (C) 2020 Hui Wu and Xiao-min Gu. This is an open access article distributed under the Creative Commons Attribution License, which permits unrestricted use, distribution, and reproduction in any medium, provided the original work is properly cited.

\begin{abstract}
This article mainly evaluates the regional innovation service capacity through the TOPSIS method. Firstly, a regional collaborative innovation network is constructed and the Yangtze River Delta region is selected for analysis. Secondly, an evaluation index is constructed for innovation service capability, fuzzy principal component analysis is used to refine quantitative and qualitative index data of innovation service capability, and the index weight is calculated. Then the region of the Yangtze River Delta is selected and TOPSIS method is used to assist in the effective decision-making process of the evaluation of innovative service capabilities. Due to the large amount of data in this article, MATLAB programming is used. Finally, through the comparative analysis of the results, countermeasures and suggestions are put forward from the perspective of the improvement of collaborative innovation service capabilities.
\end{abstract}

\section{Introduction}

The development of regional collaborative innovation is conducive to promoting the rapid development of the regional economy, optimizing the efficiency of innovation resource allocation, transforming factor-driven to innovation-driven, and promoting the overall improvement of regional economic competitiveness. The collaborative innovation model with scientific structure and active communication is conducive to the establishment of a long-term and effective scientific and technological cooperation mechanism between regions. However, due to the imbalance of resource allocation, disparity in development levels, simple repeated construction, and disorderly vicious competition among regions, the development of regional collaborative innovation has seriously hindered the promotion of regional collaborative innovation.

Collaborative innovation theory is the theoretical basis of cross-regional collaborative innovation. After Haken proposed synergetics in 1976, different scholars elaborated collaborative innovation from different angles. Kim [1] analysed the ways in which companies enhance international competitiveness by synergizing internal and external information and other innovative elements. Huber [2] believes that innovation promotes the spiral of organizational learning through process practice, so that the innovation ability in collaborative innovation is endogenous in the innovation elements. Radosevic [3] conducted research on the synergy between technological innovation and institutional change and believed that the key to determining the success of corporate innovation lies in the coordinated development of technology and many nontechnical elements. Power [4] believes that innovative ideas, processes, groups, and organizations are important elements of collaborative innovation. Morris [5] empirically studied the important impact of innovation factors on high-tech R\&D through social networks and further enriched the means for achieving collaborative innovation.

In the current research trends of regional collaborative innovation, foreign scholars' research on cross-regional collaborative innovation focuses on the research perspective, the relationship with innovation performance, and 
influencing factors. In terms of research perspectives, the perspectives of papers and patents, strategic emerging industries, and industrial ecosystems are introduced [6]. The research on the relationship between regional collaborative innovation and innovation performance focuses on the evaluation of cross-regional system innovation capability [7]. The research on the influencing factors of regional collaborative innovation is carried out from the perspective of collaborative cooperation tendency, innovation driving factors, and the cooperation relationship of innovation subjects $[8,9]$. The domestic scholars' research on cross-regional collaborative innovation ability mainly focuses on the evaluation of innovation ability, the research on the influencing factors, and mechanism and mode of innovation ability. The evaluation of cross-regional collaborative innovation capability provides different insights from different perspectives, covering research methods such as dynamic evaluation methods, comparative analysis methods, DEA, and Malmquist index $[10,11]$. The research on the influencing factors of cross-regional collaborative innovation capability has analysed its influencing factors from different research perspectives, including policy conditions, network development, resource investment, external learning, and communication. Some scholars have also explored the mechanism and model of cross-regional collaborative innovation, starting from the perspective of synergetic, undertaking industrial transfer, and technology diffusion.

Innovative service capability refers to the comprehensive evaluation of the effect of a service innovation activity by an enterprise. The innovative service capability not only reflects the effectiveness of the organization's operations and market competition but also reflects the projected development level and actual effect of the organization's projects. In recent years, research on innovative service capabilities has mostly focused on service-oriented enterprises and manufacturing industries that provide products and services at the same time $[12,13]$. In order to achieve effective market competition, not only service-oriented enterprises and manufacturing-oriented enterprises but also high-tech enterprises also strive to provide customers with perfect services and constantly carry out service innovation activities in order to improve the service quality of enterprises, thereby attracting and retaining customers, and stabilize or expand the market $[14,15]$. In addition, under the leadership of regional collaborative innovation, whether an enterprise's innovation service capability can be improved is crucial to the overall performance of the enterprise.

It can be seen by combing the relevant research at home and abroad that the existing literature provides a basic analysis framework for the expansion of innovation service capabilities and sustainable development at the practical level, but there are relatively few studies on regional innovation service capabilities, and the existing evaluation indicators. The synergy between innovation elements in the system has not been considered. One of the purposes of the measurement and evaluation of innovation service capacity is to form a more effective governance mechanism and model to promote the development of interregional system innovation, so it is necessary to study the evaluation of innovation service capacity.

Based on the current status of regional collaborative innovation development, this study is dedicated to building an evaluation model for innovation service capabilities. First, this study uses fuzzy principal component analysis to refine quantitative and qualitative indicator data for innovation service capability selection and calculates index weights. Second, this study uses TOPSIS to assist in the evaluation of innovative service capabilities. Due to the large amount of data in this article, this study was implemented using MATLAB programming. Finally, through a comparative analysis of the results, this article obtained an optimization plan for improving innovation service capabilities and proposed countermeasures and suggestions on how to guide the flow of innovation elements and improve regional collaborative innovation.

\section{Evaluation Index System Construction and Evaluation Method}

2.1. Regional Collaborative Innovation Network. Citing the ARA business network model proposed by Håkansson and Snehota [16] (Figure 1, combined with the relationship between actors and social networks involved in social network analysis, a regional collaborative innovation network is defined. The commercial network contains three elements: participants, resources, and activities. It can be seen that if you want to research a network, you must first define the network and secondly define the participants (or actors), resources, and activities (social relations). The resources and activities here can be collectively referred to as relationships, and they have an inseparable relationship with the participants. In addition, there are relationships among participants, resources, and activities. In order to facilitate measurement, they are called relationships here. As a result, the participants and relationships of a network are defined, and the boundaries of the network are clearly defined.

Participants in collaborative innovation networks usually cover enterprises, universities, scientific research institutions, intermediary services, governments, etc., but the core network of cooperative innovation networks mainly includes enterprises, universities, and scientific research institutions; networks composed of governments, intermediary services, etc., are marginal network, which can also be called a related network. The main research of this study is the core network, that is, the main body of the network is enterprises, universities, and scientific research institutions.

The regional collaborative innovation network studied in this paper selects the biopharmaceutical industry in the high-tech industry and builds a collaboration based on the relationship between companies, universities, and scientific research institutions in the biopharmaceutical industry and the application of patent (national invention patents and utility models) innovation network. The results of the visual analysis of the development of the biological medicine industry in the Yangtze River Delta are shown in Figure 2.

It can be seen from Figure 2 that the innovation ability of universities in the collaborative innovation network of the 


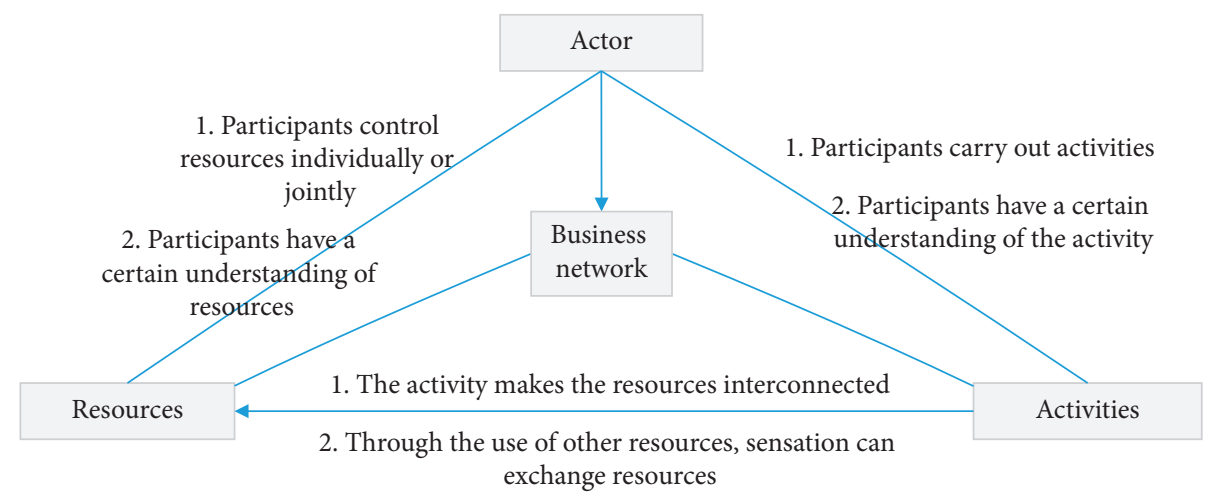

Figure 1: ARA business network model [16].

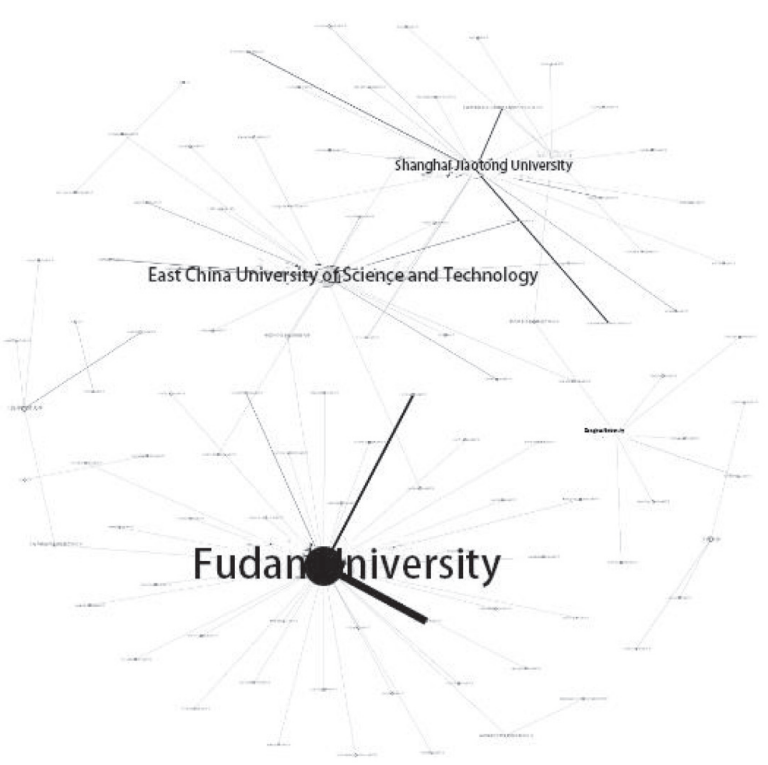

FIGURE 2: Visual analysis of the regional coordinated innovation network of the biomedical industry in the Yangtze River Delta.

biomedical industry in the Yangtze River Delta is obvious. It can be seen from the figure that the more prominent nodes are Fudan University, East China University of Science and Technology, and Shanghai Jiaotong University, which shows that the role of universities in regional collaborative innovation is far greater than that of enterprises and scientific research institutions. Moreover, the collaborative innovation cooperation between enterprises and scientific research institutions also relies on colleges and universities, and colleges and universities have outstanding effects in regional system innovation.

2.2. Construction of Evaluation Index System for Innovation Service Capability. This article takes the "China Regional Innovation Capacity Report" undertaken by the China Science and Technology Development Strategy Research Group as an example to describe the overview of the innovation capacity evaluation index system. First of all, the innovation subjects of the regional innovation capability framework are universities, R\&D institutions, enterprises, intermediary institutions, and governments. Secondly, the framework takes into account the flow of innovation elements among innovation entities and the innovation capability of the innovation entities themselves. Thirdly, the framework emphasizes the importance of the construction of an innovation environment and points out that the government needs to carry out function transformation to promote technological innovation of enterprises. Finally, the innovation capability framework takes into account the three dimensions of regional development stock, relative level, and growth rate. On the basis of the above analysis framework, we constructed five first-level indicators, 20 second-level indicators, 40 third-level indicators, and 137 fourth-level indicators including knowledge creation, knowledge acquisition, enterprise innovation, innovation environment, and innovation performance. Regional innovation capability index system.

On this basis, combined with the needs of innovation service capability assessment, the five indicators of knowledge creation, knowledge acquisition, enterprise innovation, innovation environment, and innovation performance are assisted in three aspects: regional collaborative innovation input, regional collaborative innovation output, and regional collaborative innovation conditions. Construction of indicators, specifically when establishing an evaluation indicator system, selects indicators from four aspects: simplicity, relativity, representativeness, comparability, and feasibility of indicators $[12,13,15,17]$. The specific evaluation index system for innovation service capability is shown in Table 1.

\subsection{Evaluation Method of Innovation Service Capability in the Yangtze River Delta}

2.3.1. Selection of TOPSIS Method. Simply simplifying the data and reducing the dimensions cannot tell whether the decision is effective. The problem of innovation service capability evaluation belongs to the category of multiobjective decision-making, so the problem can only be solved effectively by using good decision-making methods. TOPSIS (Technology for Order Preference by Similarity to an Ideal Solution) method is an analysis method for solving multiobjective decision-making problems with limited 
TABLE 1: Innovation service capability index system.

\begin{tabular}{|c|c|c|c|c|c|}
\hline First-level indicators & $\begin{array}{l}\text { Secondary } \\
\text { indicators }\end{array}$ & Third-level indicators & Unit & Code & Citations \\
\hline \multirow{10}{*}{$\begin{array}{l}\text { Regional collaborative innovation } \\
\text { investment }\end{array}$} & \multirow{2}{*}{ Enterprise } & Number of enterprises & Pc & $\mathrm{X} 1$ & {$[12]$} \\
\hline & & R\&D personnel & People & $\mathrm{X} 2$ & {$[13]$} \\
\hline & \multirow{2}{*}{ Efficient } & Number of universities & Pc & $\mathrm{X} 3$ & {$[15]$} \\
\hline & & R\&D personnel & People & $\mathrm{X} 4$ & [17] \\
\hline & \multirow{4}{*}{ R\&D institutions } & Number of R\&D institutions & Pc & $\mathrm{X} 5$ & \\
\hline & & R\&D personnel & People & X6 & \\
\hline & & Government finance technology grant & Billion & $\mathrm{X} 7$ & \\
\hline & & Government financial project appropriation & Billion & $\mathrm{X} 8$ & \\
\hline & \multirow[t]{2}{*}{ Government } & $\begin{array}{l}\text { Government science and technology project } \\
\text { implementation funds }\end{array}$ & Billion & X9 & \\
\hline & & Scientific papers & Article & $\mathrm{X} 10$ & \\
\hline \multirow{5}{*}{$\begin{array}{l}\text { Regional collaborative innovation } \\
\text { output }\end{array}$} & \multirow{5}{*}{ Results } & Patent application & Item & $\mathrm{X} 11$ & \\
\hline & & Patent ownership transfer & Item & $\mathrm{X} 12$ & \\
\hline & & Form an expert or industry standard & Item & $\mathrm{X} 13$ & \\
\hline & & New product sales revenue & Billion & $\mathrm{X} 14$ & \\
\hline & & Patent transfer income & Billion & $\mathrm{X} 15$ & \\
\hline \multirow{4}{*}{$\begin{array}{l}\text { Assistance in regional collaborative } \\
\text { innovation }\end{array}$} & \multirow{3}{*}{ Economic basis } & GDP & Billion & $\mathrm{X} 16$ & \\
\hline & & Financial institution loan balance & Billion & $\mathrm{X} 17$ & \\
\hline & & Employed population & People & $\mathrm{X} 18$ & \\
\hline & Resident life & Number of college graduates or above & People & X19 & \\
\hline
\end{tabular}

solutions [18]. Its logical relationship is relatively simple and clear, with good interactivity and easy implementation. At present, this method has been applied to the research of innovation service capability evaluation. Therefore, the reason for choosing the TOPSIS algorithm in this study is as follows:

(1) The indicators in this article are more objective, and it is not suitable to choose subjective evaluation methods, such as intuitive judgment method and linear weighting method

(2) The evaluation results in this paper do not involve cost and efficiency, so the activity cost method and data envelope algorithm are not used

(3) The indicator data in this paper are relatively small, so if the artificial neural network algorithm is not used, the results will not converge

(4) The indicators in this article are clear and there is no greater ambiguity, so fuzzy comprehensive evaluation method and gray system theory method are not used

\section{Model Principle}

3.1. Principle of Fuzzy Principal Component Analysis. Principal component analysis is a statistical analysis method that converts multiple variables into a few principal components through dimensionality reduction techniques, which uses the original more evaluation indicators with simplified comprehensive principal component indicators. Instead, the comprehensive indicator retains most of the information of the original variables and is not related to each other, which can simplify complex problems. The fuzzy principal component analysis method is based on the variance contribution rate of the principal component combined with the fuzzy theory to obtain a reasonable correction weight. The specific process is as follows:
After standardizing the secondary indicators of the original data, perform weighted synthesis to obtain the evaluation value of the primary indicators:

$$
\begin{array}{r}
\eta_{i j}=\frac{a_{i j}}{\sqrt{\sum_{i=1}^{n}\left(a_{i j}\right)^{2}}}, \quad \text { where } i=1,2, \ldots, n ; \\
j=1,2, \ldots, k .
\end{array}
$$

In the formula, $a_{i j}$ represents the evaluation value of the $j$-th secondary index of the $i$-th region and $\eta_{i j}$ represents the evaluation value of the $i$-th secondary index of the $j$-th region after normalization. The comprehensive weighting of the secondary indicators yields $x_{i j}^{*}=w_{i j} \eta_{i j}$, where $w_{i j}$ is the weight of the secondary indicators in the corresponding indicators.

Principal component analysis of first-level indicators Initial sample matrix $X^{*}=\left(x_{i j}^{*}\right)_{n \times p}$, where $i=1,2, \ldots, n ; j=1,2, \ldots, p$

(1) Standardize the index according to the $x_{i j}=x_{i j}^{*}-$ $\overline{x_{j}^{*}} / s_{j}^{*}$ formula to obtain a standardized evaluation matrix $X=\left(x_{i j}\right)_{n \times p}$. In the formula, $\overline{x_{j}^{*}}$ and $s_{j}^{*}$ are the sample mean and sample standard deviation of the $j$ index, respectively.

(2) Calculate the correlation coefficient matrix $R_{p \times p}$, eigenvalue $\lambda_{1} \geq \cdots \geq \lambda_{p} \geq 0$, and normalized eigenvector $E_{i j}$ between indicators.

(3) Using the unit feature vector corresponding to the previous eigenvalue of $p$, the principal component of $p$ can be expressed as a linear combination of the original indicators, thereby obtaining the principal component equation: 


$$
F_{i j}=X_{i j} E_{i j}, \quad i=1,2, \ldots, n ; j=1,2, \ldots, p .
$$

(4) The variance contribution rate of the $j$ principal component is $\mu_{j}=\lambda_{j} / \sum_{j=1}^{p} \lambda_{j}$. When the cumulative variance contribution rate $\mu=\sum_{j=1}^{m} \mu_{j}$ reaches a certain value (generally not less than $85 \%$ ), the first $m$ principal components $F_{i 1}, F_{i 2}, \ldots, F_{i m}(i=1,2$, $\ldots, n)$ are taken, that is, the $m$ principal components are considered to reflect the information of the original $p$ evaluation indicators with fewer indicators.

(5) Use the variance contribution rate of each principal component as the initial weight, and modify the initial weight to obtain the final weight. The reason is that when evaluating the original indicators, each expert gives the number of weight intervals of each indicator and the optimism of the collaborative innovation ability of each candidate area according to the needs of the enterprise. For this purpose, it is necessary to calculate the weight $W_{i}=\left\{w_{i}\right\}$, $i=1,2, \ldots, n ; j=1,2, \ldots, m$ that corrects the weight of the principal component and correct the weight of the principal component. The specific correction process is as follows:

$$
B\left(\left[p_{j}, q_{j}\right]\right)=\left(1-a_{j}\right) \frac{p_{j}-p_{\min }}{p_{\max }-p_{\min }}+a_{j} \frac{q_{j}-q_{\min }}{q_{\max }-q_{\min }} .
$$

The weight fuzzy set $B\left\{\left[p_{1}, q_{1}\right],\left[p_{2}, q_{2}\right], \ldots,\left[p_{n}, q_{n}\right]\right\}$ is the value of the weight interval of the evaluation index, and $B\left(\left[p_{n}, q_{n}\right]\right)$ indicates the relative importance of the index. In the formula, $p_{\min }=\min _{1<j<n} p_{j}, p_{\max }=$ $\max _{1<j<n} p_{j}, q_{\min }=\min _{1<j<n} q_{j}, q_{\max }=\max _{1<j<n} q_{j}$, and $a_{j}$ represents the optimistic coefficient for the region, $0<a_{j}<1$.

Therefore, normalizing the important membership degree can get the index weight as follows:

$$
w_{i j}=\frac{B\left(\left[p_{j}, q_{j}\right]\right)}{\sum_{j=1}^{m} B\left(\left[p_{j}, q_{j}\right]\right)}, \quad i=1,2, \ldots, n .
$$

(6) Amend the preliminary weight to obtain the final weight of the regional innovation capability evaluation index:

$$
\beta_{i}=\frac{w_{i j} \mu_{j}}{\sum_{j=1}^{m} w_{i j} \mu_{j}}, \quad i=1,2, \ldots, n
$$

3.2. Principle of TOPSIS Evaluation Method. Similarity to ideal solution sorting method TOPSIS is a commonly used scheme limited multiobjective decision analysis method, which has the ideal solution and negative ideal solution to sort the program set by means of a multiproperty issue. The ideal solution is a virtual best solution that does not exist in the solution set, and each of its attribute values is the best value in the solution; the negative ideal solution is the virtual worst solution, and each attribute value is the best in the solution. Poor value. All the alternatives in the solution set are compared with the distance between the ideal solution and the negative ideal solution. The solution that is close to the ideal solution and far from the negative ideal solution is the best solution. The specific evaluation steps are as follows.

3.2.1. Construct the Initial Matrix. There are $n$ candidate programs and $m$ evaluation indicators, and $x_{i j}^{*}$ represents the evaluation value of the $j$ index of the $i$ program, and the initial matrix $V$ of the principal component obtained by $V=$ $X^{*^{T}} U$ ( $U$ is the coefficient matrix) is standardized according to $v_{i j}=v_{i j}^{*} / \sqrt{\sum_{i=1}^{N}\left(v_{i j}^{*}\right)^{2}}, i=1,2, \ldots, n ; j=1,2, \ldots, m$. The standardized matrix $A=\left(a_{i j}\right)_{n \times m}$ is obtained.

\subsubsection{Construct Weighted Normalization Matrix.}

$$
B=A^{T} W=\left(\begin{array}{cccc}
w_{11} a_{11} & w_{12} a_{12} & \ldots & w_{1 m} a_{1 m} \\
w_{21} a_{21} & w_{22} a_{22} & \ldots & w_{2 m} a_{2 m} \\
\ldots & \ldots & \ldots & \ldots \\
w_{n 1} a_{n 1} & w_{n 2} a_{n 2} & \ldots & w_{n m} a_{n m}
\end{array}\right) .
$$

Among them $W_{n \times m}$ are the correction weights obtained by fuzzy principal component analysis.

3.2.3. Determine the Ideal Solution $B^{+}$and Negative Ideal Solution $B^{-}$.

$$
\begin{aligned}
& B^{+}=\left[\max _{i} b_{i j} \mid j \in J\right]=\left[b_{1}^{+}, b_{2}^{+}, b_{j}^{+}, \ldots, b_{m}^{+}\right], \quad i=1,2, \ldots, n, \\
& B^{-}=\left[\min _{i} b_{i j} \mid j \in J\right]=\left[b_{1}^{-}, b_{2}^{-}, b_{j}^{-}, \ldots, b_{m}^{-}\right], \quad i=1,2, \ldots, n .
\end{aligned}
$$

3.2.4. Calculate the Distance. The distance between the evaluation value and the ideal solution and the negative ideal solution is given by

$$
s_{i}^{+}=\sqrt{\sum_{j=1}^{m}\left(b_{i j}-b_{j}^{+}\right)^{2}}, s_{i}^{-}=\sqrt{\sum_{j=1}^{m}\left(b_{i j}-b_{j}^{-}\right)^{2}} .
$$

3.2.5. Determine the Relative Proximity $C_{i}$.

$$
C_{i}=\frac{s_{i}^{-}}{s_{i}^{-}+s_{i}^{+}}, \quad i=1,2, \ldots, n, 0 \leq C_{i} \leq 1 .
$$

3.2.6. Sorting Preference. The schemes are sorted and selected in the order of $C_{i}$ from large to small, and the relative closeness $C_{i}$ selects the optimal scheme, which is the area with the highest innovation service capability. 


\section{Case Study}

In May 2010, the State Council formally approved the implementation of "the Regional Plan for the Yangtze River Delta Region". The document states that the Yangtze River Delta includes Shanghai, Jiangsu, and Zhejiang. In 2014, the "Guiding Opinions of the State Council on Relying on the Golden Waterway to Promote the Development of the Yangtze River Economic Belt" also made it clear for the first time to include Anhui Province in the Yangtze River Delta to participate in development. In May 2016, the Standing Committee of the State Council formally adopted the "Development Plan for the Urban Agglomeration of the Yangtze River Delta Region." The plan clearly mentioned that Shanghai should play a leading role to promote the common development of various metropolitan areas, including Nanjing Metropolitan Area, Hangzhou Metropolitan Area, Hefei Metropolitan Area, Suxi Changzhou Metropolitan Area, and Ningbo Metropolitan Area. The Yangtze River Delta urban agglomeration is complete with large, medium, and small cities, with one megacity, one megacity, 13 large cities, 9 medium cities, and 42 small cities. The Yangtze River Delta is a typical region for regional collaborative innovation development, and this study uses this as an object for case analysis.

4.1. Expert Questionnaire Survey and Data Collection. Table 2 shows the original data and initial weights for enterprises to evaluate suppliers, and Table 3 shows the result of weighted standardization of the secondary indicators of their original data. The expert survey method was used to verify the construction of innovative service capabilities in this study, and then the corresponding indicator data were selected. The data involved in this article were all from the China Statistical Yearbook, the China Science and Technology Yearbook, and the statistical yearbooks of various provinces and cities.

4.2. Fuzzy Principal Component Analysis. According to the initial evaluation weight interval of each index: $[17,23],[11$, $18],[6,9]$, we use the fuzzy algorithm to obtain the modified weight $W_{i}$ and the final principal component weights $\beta_{j}$, respectively:

$$
\begin{aligned}
& a_{1}=0.95 W_{1}=(0.3339,0,0.4965,0.1696) \beta_{1}=(0.5299,0,0.3836,0.0865), \\
& a_{2}=0.76 W_{2}=(0.3361,0,0.4834,0.1805) \beta_{2}=(0.5340,0,0.3739,0.0921), \\
& a_{3}=0.82 W_{3}=(0.3354,0,0.4875,0.1771) \beta_{3}=(0.5327,0,0.3770,0.0903), \\
& a_{4}=0.65 W_{4}=(0.3373,0,0.4762,0.1865) \beta_{4}=(0.5362,0,0.3686,0.0952) .
\end{aligned}
$$

Among them, $a_{1}, a_{2}, a_{3}$, and $a_{4}$ are known expert's optimistic coefficients for innovation service capability.

4.3. TOPSIS Evaluation. In order to adapt to the problem of index selection and evaluation of innovation service capability with many indexes, this article uses MATLAB programming to implement the TOPSIS algorithm, which not only saves time, but also provides results more accurately. The specific calculation process and results are as follows.

4.3.1. Construct the Initial Matrix. In this paper, there are 4 candidate programs, namely, 4 regions and 3 evaluation indicators. $x_{i j}$ represents the evaluation value of the $j$ index of the $i$ program. The initial evaluation matrix $V$ is obtained by multiplying the initial matrix $X$ by the coefficient matrix U:

$$
V=\left(\begin{array}{ccc}
97.6278 & 76.3622 & 79.9790 \\
40.1815 & 112.8293 & 37.4480 \\
9.4977 & 41.3866 & 48.2996 \\
89.6354 & 37.2349 & 70.5447
\end{array}\right) .
$$

Normalize according to $v_{i j}=v_{i j}^{*} / \sqrt{\sum_{i=1}^{6}\left(v_{i j}^{*}\right)^{2}}$, $j=1,2, \ldots, 4$ and get a standardized matrix $A=\left(a_{i j}\right)_{4 \times 3}$.

\subsubsection{Construct Weighted Normalization Matrix.}

$$
B=A^{T} W=\left(\begin{array}{lll}
0.2873 & 0.0462 & 0.2367 \\
0.1192 & 0.0354 & 0.1080 \\
0.0281 & 0.0116 & 0.1405 \\
0.2669 & 0.0416 & 0.2006
\end{array}\right) \text {. }
$$

$$
\text { Among them } W=\left(\begin{array}{lll}
0.5299 & 0.0865 & 0.3836 \\
0.5340 & 0.0921 & 0.3739 \\
0.5327 & 0.0903 & 0.3770 \\
0.5362 & 0.0952 & 0.3686
\end{array}\right) \text { are the }
$$

correction weights obtained by fuzzy principal component analysis.

4.3.3. Determine the Ideal Solution $B^{-}$and Negative Ideal Solution $B^{-}$. From $B^{+}=\left[\max _{i} b_{i j} \mid j \in J\right]=\left[b_{1}^{+}, b_{2}^{+}, \ldots\right.$, $\left.b_{3}^{+}\right], i=1,2, \ldots, 4$, get

$$
B^{+}=\left[\begin{array}{lll}
0.3356 & 0.2367 & 0.0462
\end{array}\right] .
$$


TABle 2: Expert survey.

\begin{tabular}{|c|c|c|c|c|c|c|c|}
\hline \multirow{2}{*}{$\begin{array}{l}\text { First-level indicators } \\
\text { Name }\end{array}$} & \multirow[b]{2}{*}{ Weights } & \multicolumn{2}{|c|}{ Secondary indicators } & \multirow{2}{*}{ Shanghai } & \multirow{2}{*}{ Jiangsu } & \multirow{2}{*}{ Zhejiang } & \multirow{2}{*}{ Anhui } \\
\hline & & Name & Weights & & & & \\
\hline \multirow{4}{*}{ Regional collaborative innovation investment } & \multirow{4}{*}[17,23]{} & Enterprise & 50 & 128 & 130 & 110 & 140 \\
\hline & & Efficient & 20 & 90 & 90 & 90 & 80 \\
\hline & & $\mathrm{R} \& \mathrm{D}$ institutions & 30 & 21 & 30 & 15 & 40 \\
\hline & & Government & 37 & 21 & 30 & 15 & 40 \\
\hline \multirow{2}{*}{ Regional collaborative innovation output } & \multirow{2}{*}[11,18]{} & Results & 35 & 80 & 120 & 170 & 99 \\
\hline & & Income & 30 & 34 & 50 & 60 & 30 \\
\hline \multirow{2}{*}{ Assistance in regional collaborative innovation } & \multirow{2}{*}[6,9]{} & Economic basis & 26 & 34 & 50 & 60 & 30 \\
\hline & & Resident life & 14 & 23 & 11 & 15 & 20 \\
\hline
\end{tabular}

TABLE 3: Weighted synthesis of secondary indicators.

\begin{tabular}{|c|c|c|c|c|c|}
\hline $\begin{array}{l}\text { First-level indicators } \\
\text { Name }\end{array}$ & Weights & Shanghai & Jiangsu & Zhejiang & Anhui \\
\hline Regional collaborative innovation investment & {$[17,23]$} & 41.3956 & 40.08919 & 40.9547 & 41.86353 \\
\hline Regional collaborative innovation output & {$[11,18]$} & 37.08671 & 26.16658 & 39.15287 & 41.84066 \\
\hline Assistance in regional collaborative innovation & {$[6,9]$} & 40.16341 & 48.53234 & 30.64865 & 43.26791 \\
\hline
\end{tabular}

From $\quad B^{-}=\left[\min _{i} b_{i j} \mid j \in J\right]=\left[b_{1}^{-}, b_{2}^{-}, \ldots, b_{3}^{-}\right], i=1,2$, $\ldots, 4$, get

$$
B^{-}=\left[\begin{array}{lll}
0.0281 & -0.0132 & 0.0116
\end{array}\right] \text {. }
$$

4.3.4. Calculate the Distance between the Evaluation Value and the Ideal Solution and the Negative Ideal Solution. From $s_{i}^{+}=\sqrt{\sum_{j=1}^{3}\left(v_{i j}-v_{j}^{+}\right)^{2}}, i=1,2, \ldots, 4$, get the distance between the evaluation value and the ideal solution:

$$
s^{+}=\left[\begin{array}{llll}
0.0483 & 0.2521 & 0.3241 & 0.0777
\end{array}\right] .
$$

From $s_{i}^{-}=\sqrt{\sum_{j=1}^{3}\left(v_{i j}-v_{j}^{-}\right)^{2}}, i=1,2, \ldots, 4$, get the distance between the evaluation value and the ideal solution:

$$
s^{+}=\left[\begin{array}{llll}
0.3618 & 0.1535 & 0.1537 & 0.3220
\end{array}\right] .
$$

\subsubsection{Determine the Relative Proximity}

C. From $C_{i}=s_{i}^{-} / s_{i}^{-}+s_{i}^{+}, i=1,2, \ldots, 4,0 \leq C_{i} \leq 1$, get:

$$
C=\left[\begin{array}{llll}
0.8822 & 0.3785 & 0.8055 & 0.3217
\end{array}\right] \text {. }
$$

Think of the value of $C_{i}$ as a score for the innovation service capability of each region, and select a better region. Because of $C_{1}>C_{3}>C_{2}>C_{4}$, the first area, Shanghai, has a higher innovation service capability than other areas.

\section{Conclusions and Recommendations}

5.1. Research Conclusion. The innovation of this study mainly lies in the innovation of methods. In the regional collaborative innovation network, the evaluation of innovation service capability is very important. At present, the most commonly used methods are fuzzy clustering, DEA method, AHP method, and fuzzy analytic hierarchy process. When analyzing these methods, it is not difficult to find that the current innovation service capacity evaluation involves too many indicators. The calculation process becomes very complex, even difficult to calculate. The use of fuzzy principal component analysis combined with TOPSIS can objectively select regional collaborative innovation indicators, which has higher accuracy, simpler principles, and more objective conclusions, and when the indicators increase, this method performs data processing. Effective decision-making has more advantages. When there are a lot of data, use statistical software to process the data, and implement the algorithm through MATLAB programming, you can quickly get scientific results, so you can make decisions quickly. Of course, this method can be applied not only to the evaluation of innovative service capabilities, but also to other aspects, such as supplier selection, route selection, and location selection of distribution centers.

This article takes the biomedical industry as an example in the regional collaborative innovation network. It can be found that universities play an important role in the network, which shows that companies tend to cooperate with universities to innovate, and they must pay attention to and play a role in the improvement of innovation service capabilities. The important role of universities in the process is innovation creation and dissemination. Through the index construction and evaluation process of innovation service capacity, it can be found that among the four regions in the Yangtze River Delta, Shanghai, Jiangsu Province, Zhejiang Province, and Anhui Province, Shanghai has the strongest innovation service capacity, followed by Zhejiang Province, Then came Jiangsu Province, and finally Anhui Province, and the conclusions of the study are in good agreement with the actual situation in the Yangtze River Delta.

5.2. Suggestions. Finally, according to the research conclusion of this paper, the following two countermeasures and suggestions are proposed to enhance the innovation service capability. 
First of all is the optimization suggestions on the innovation level of industry-university-research cooperation: the improvement of regional collaborative innovation capabilities needs to be optimized from the perspective of regional and collaborative innovation environments, strengthen regional cooperation, increase the exchange and cooperation of innovations, avoid overlapping information, and enjoy the support of multiple policies and multiple innovation environments. At the same time, Shanghai, as a leader in the economic development of the Yangtze River Delta, should play its leading role in creating a globally influential scientific and technological innovation center and realize the common development of the region. The independent innovation activities of universities, enterprises, and scientific research institutions are not preferred. The optimization of the environment requires many efforts. The core body of the industry-university-research cooperative innovation network is an important participant and an important builder of the network. Financial institutions and intermediaries should also play their roles to form an open and dynamic innovation environment; an industry-university-research cooperation innovation platform is established to maximize resource utilization efficiency. Innovation requires the cooperation and resource sharing of the core and related subjects, so a mature operating mechanism is needed to integrate the resources of universities, enterprises, scientific research institutions, governments, financial institutions, and intermediary institutions to optimize the efficiency of resource utilization, so establishing a collaborative innovation platform is crucial.

Secondly, the government should optimize from the level of policies and regulations, introduce corresponding encouragement policies, and give more preferential tax policies to promote the creation and development of innovation. In addition to supporting and coordinating functional $\mathrm{R} \& \mathrm{D}$ transformation platforms, in addition to optimization at the legal level, online and offline platforms can be established, combined with existing advanced information technology, so that the main body of the industryuniversity-research cooperation innovation network can better share resources and technology, a corresponding biomedical R\&D and transformation platform is established to help companies innovate better and promote faster marketization of innovations. The government plays an important role in this process because the public service platform must protect public welfare and encourage the research and development of shared technologies, so the government plays a vital role in it.

\section{Data Availability}

The data involved in this article were all from the China Statistical Yearbook, the China Science and Technology Yearbook, and the statistical yearbooks of various provinces and cities. Among them, the data in Figure 2 come from the patent search database of the China Intellectual Property Office. The data used to support the findings of this study were supplied by author under license and so cannot be made freely available. Requests for access to these data should be made to [Xiao-min Gu, guxiaomin@lixin.edu.cn].

\section{Conflicts of Interest}

The authors declare that they have no conflicts of interest.

\section{References}

[1] I. Kim, "Managing Korea's system of technological innovation," Interfaces, vol. 23, no. 6, pp. 13-24, 1993.

[2] G. Huber, "Synergies between organizational learning and creativity \& innovation," Creativity and Innovation Management, vol. 7, no. 1, pp. 3-8, 1998.

[3] S. Radosevic, "Defining systems of innovation: A methodological discussion," Technology in Society, vol. 20, no. 1, pp. 75-86, 1998.

[4] L. Power, "The missing link: Technology, investment, and productivity," Review of Economics and Statistics, vol. 80, no. 2, pp. 300-313, 1998.

[5] B. Morris, "High technology development: Applying a social network paradigm," Journal of New Business Ideas and Trends, vol. 4, no. 1, pp. 45-59, 2006.

[6] I. De Noni, L. Orsi, and F. Belussi, "The role of collaborative networks in supporting the innovation performances of lagging-behind European regions," Research Policy, vol. 47, no. 1, pp. 1-13, 2018.

[7] A. Marasco, M. De Martino, F. Magnotti, and A. Morvillo, "Collaborative innovation in tourism and hospitality: A systematic review of the literature," International Journal of Contemporary Hospitality Management, vol. 30, no. 6, pp. 2364-2395, 2018.

[8] F. Caviggioli, "Technology fusion: Identification and analysis of the drivers of technology convergence using patent data," Technovation, vol. 55-56, no. 6, pp. 22-32, 2016.

[9] S. Han, G. M. Yoo, and S. Kwak, "'A comparative analysis of regional innovation characteristics using an innovation actor framework," Science, Technology and Society, vol. 23, no. 1, pp. 137-162, 2018.

[10] C. Lindsay, P. Findlay, J. McQuarrie, M. Bennie, E. D. Corcoran, and R. Van Der Meer, "Collaborative innovation, new technologies, and work redesign," Public Administration Review, vol. 78, no. 2, pp. 251-260, 2018.

[11] L. Zhen, "Tactical berth allocation under uncertainty," European Journal of Operational Research, vol. 247, no. 3, pp. 928-944, 2015.

[12] D. C. Bello, L. P. Radulovich, R. G. Javalgi, R. F. Scherer, and J. Taylor, "Performance of professional service firms from emerging markets: role of innovative services and firm capabilities," Journal of World Business, vol. 51, no. 3, pp. 413-424, 2016.

[13] O. F. Bustinza, E. Gomes, F. Vendrell-Herrero, and T. Baines, "Product-service innovation and performance: The role of collaborative partnerships and R \& D intensity," $R$ \& $D$ Management, vol. 49, no. 1, pp. 33-45, 2019.

[14] L. Zhen, "Modeling of yard congestion and optimization of yard template in container ports," Transportation Research Part B: Methodological, vol. 90, pp. 83-104, 2016.

[15] V. Jayaraman and Z. Liu, "Aligning governance mechanisms with task features to improve service capabilities---an empirical study of professional service outsourcing in India," Operations Management Research, vol. 12, no. 1-2, pp. 19-39, 2019.

[16] H. Håkansson and I. Snehota, "Developing relationships in business networks," Journal of Purchasing, pp. 1-261, 1995.

[17] R. P. J. Rajapathirana and Y. Hui, "Relationship between innovation capability, innovation type, and firm 
performance," Journal of Innovation \& Knowledge, vol. 3, no. 1, pp. 44-55, 2018.

[18] C. L. Hwang and K. Yoon, "Multiple attribute decision making," Lecture Notes in Economics \& Mathematical Systems, vol. 404, no. 4, pp. 287-288, 1981. 